\title{
Low-Noise Amplifiers for W-Band and D-Band Passive Imaging Systems in SiGe BiCMOS Technology
}

\author{
Berktug Ustundag*, Esref Turkmen*, Barbaros Cetindogan ${ }^{\#}$, Alper Guner*, Mehmet Kaynak*, Yasar Gurbuz ${ }^{*}$ \\ \#IHP, Im Technologiepark 25, 15236 Frankfurt (Oder), Germany \\ *Sabanci University, Orta Mahalle, Universite Cd. No:27, 34956 Istanbul, Turkey \\ yasaresabaciuniv.edu
}

\begin{abstract}
In this paper, two wideband and low power mmwave LNAs implemented in a $0.13 \mu \mathrm{m}$ SiGe BiCMOS technology are presented. The $\mathrm{W}$-band LNA has $22.3 \mathrm{~dB}$ peak gain, $17 \mathrm{GHz}$ 3-dB bandwidth (BW) and $8 \mathrm{~mW}$ of power consumption whereas the D-Band LNA achieves $25.3 \mathrm{~dB}$ peak gain, $44 \mathrm{GHz} 3-\mathrm{dB}$ BW while consuming $30 \mathrm{~mW}$ of power. Input and output of the LNAs are wideband matched to $50 \Omega$ in their respective frequency bands. Using the measured gains, the effective noise bandwidths are calculated to be $33.8 \mathrm{GHz}$ for the $\mathrm{W}$-band and $58.9 \mathrm{GHz}$ for the Dband LNAs. Measurement results indicate that the LNAs are suitable for low power and wideband radiometer systems.

Index Terms - millimeter wave integrated circuits, low-noise amplifier, millimeter wave radiometry.
\end{abstract}

\section{INTRODUCTION}

Passive imaging systems operating at millimeter-wave and $\mathrm{THz}$ region have been gaining attention in recent years due the advancements in monolithic microwave integrated circuits (MMICs) which are capable of operating at low atmospheric attenuation windows such as 94, 140 and $220 \mathrm{GHz}$. These systems can detect thermal radiation emitted from the objects and provide an image of the scene especially in low visibility conditions (fog, dust, rain etc.), given that the system has high enough temporal sensitivity [1]. For this reason, radiometer systems enable critical applications such as concealed weapon detection [2], remote sensing [3] and non-invasive medical imaging [4]. However, achieving a high sensitivity detection, or low enough noise equivalent temperature difference (NETD), remains a challenging issue.

The limiting factor for designing a low NETD system arises from the $1 / \mathrm{f}$ noise of the active components. However, even if these fluctuations are minimized using calibration techniques, one still needs to improve the RF bandwidth of the receiver as well as the system noise temperature. Consequently, a high gain and wide bandwidth low noise amplifier (LNA) to suppress the noise of the power, becomes crucial.

Silicon based technologies such as CMOS and SiGe BiCMOS have advanced tremendously, achieving $\mathrm{f}_{\mathrm{t}} / \mathrm{f}_{\max }$ of more than $300 \mathrm{GHz}$, which facilitates the design of high performance millimeter-wave circuits at relatively low cost and similar performance to its III-IV counterparts. In this work, we present wideband LNAs, operating at W-Band $(75-110 \mathrm{GHz})$ and D-Band (110-170 GHz) using IHP's SG13G2 0.13 $\mu \mathrm{m}$ SiGe BiCMOS process featuring HBTs at 300 and $500 \mathrm{GHz} \mathrm{f}_{\mathrm{t}}$ and $\mathrm{f}_{\max }$ respectively.

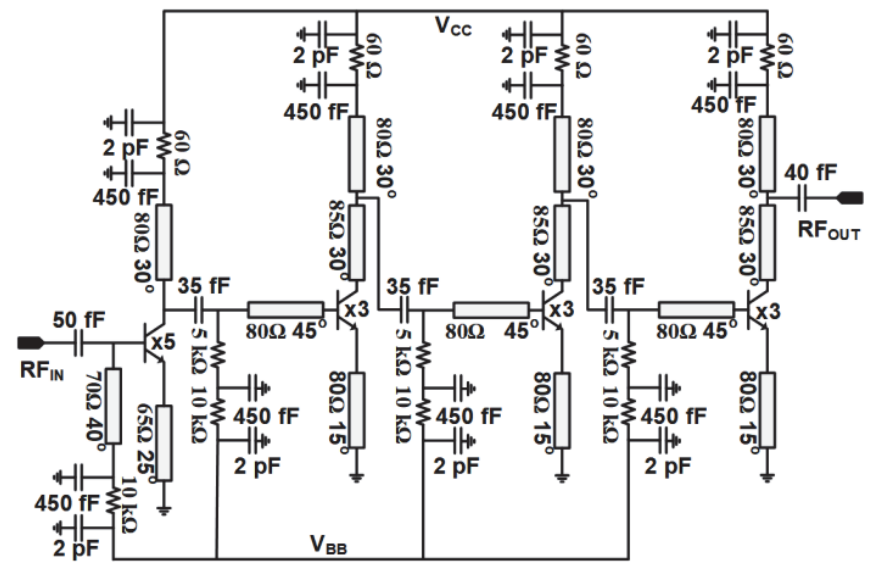

Fig. 1. Circuit schematic of the W-band low-noise amplifier (Electrical lengths are given at $94 \mathrm{GHz}$ ).

\section{CIRCUIT DESIGN}

\section{A. W-band Low Noise Amplifier}

The circuit schematic of the W-band LNA is shown in Fig. 1. Four-stage common-emitter (CE) topology is sufficient for Wband to achieve $20 \mathrm{~dB}$ or higher gain, and CE provides lower NF than a cascode stage. First stage of the LNA was designed using the simultaneous power and noise matching technique. Optimum transistor number was chosen to be $\mathrm{x} 5$ and collector current $\left(\mathrm{I}_{\mathrm{C}}\right)$ is set to $1.2 \mathrm{~mA}$ for a tradeoff between minimum noise figure and gain. Using a shunt shorted transmission line at the base and an emitter degeneration, it is possible to avoid any series transmission line (TL) while still allowing for $50 \Omega$ input over a wide bandwidth.

The remaining stages are all identical. Emitter degeneration inductance were reduced to a smaller value and $\mathrm{I}_{\mathrm{C}}$ is increased to $1.7 \mathrm{~mA}$ to achieve higher gain per stage. All the base biases were applied over large poly resistors. RF shorts were implemented using $450 \mathrm{fF}$ metal-insulator-metal (MIM) capacitors with adjusted geometry such that they self- resonate close to W-band. To ensure circuit stability at all frequencies, small silicide resistors were used on the bias lines, and secondary capacitors were added on the order of several $\mathrm{pFs}$. All the bias planes were sandwiched between two ground planes, i.e. metal 1, 3, 5, TopMetal 2 were used for ground whereas metal 2, 4 and TopMetall were used as bias planes. 


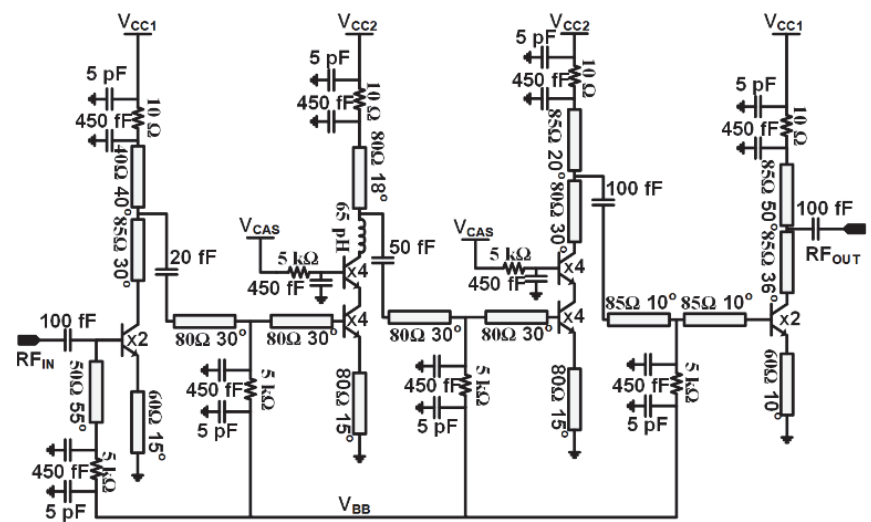

Fig. 2. Circuit schematic of the D-band low-noise amplifier (Electrical lengths are given at $140 \mathrm{GHz}$ ).

This sandwiched configuration adds also several $\mathrm{pFs}$ to bypass network in addition to the MIM capacitors. All the transmission lines were implemented using microstrip lines with TopMetal2Metall configuration. EM simulations were performed using ADS Momentum excluding the secondary capacitor banks and metal fillers.

\section{B. D-band Low Noise Amplifier}

The schematic of the 4-stage D-band LNA is shown in Fig. 2. Similar approaches were made with the W-band LNA in this design; however, the topologies of the second and third stages were changed to keep the gain above $20 \mathrm{~dB}$ across the entire Dband. Consequently, power consumption constraints are also relaxed compared to $\mathrm{W}$-band as a tradeoff since available gain per stage is much lower.

A cascode stage could provide 3-4 $\mathrm{dB}$ more compared to $\mathrm{CE}$, as a result the two middle stages were implemented as cascode amplifiers. At the input, CE was chosen over cascode for wideband input matching as well as to achieve lower NF since the $\mathrm{CE}$ provides better noise performance than the cascode configuration. Similarly, the output was also implemented as $\mathrm{CE}$ for improved output matching. Interstage matchings were designed using T-type networks, utilizing high characteristic impedance microstrip lines along with MIM capacitors. The collector current of the first stage was set to $2.2 \mathrm{~mA}$ to optimize the noise performance while achieving acceptable gain to suppress the noise of the following stages. $4.4 \mathrm{~mA}$ and $3 \mathrm{~mA}$ collector currents were set for the cascode stages and the last stage, respectively, to achieve high gain.

All the transmission lines were implemented using microstrip lines with TopMetal2-Metall configuration. Parasitic effects are major concerns at mm-wave frequencies. Therefore, full chip simulations were performed including the vias, capacitors and the bypass networks. Parasitic capacitances due to the RF pads could also significantly deteriorate the input matching of the LNAs, and the NF of the chips would increase because of the loss at the input due to the parasitic capacitance of the input RF pad. To avoid this problem, custom RF pads were designed using just TopMetal 2 with a reduced area while still allowing probes to be landed properly are included in the structure.

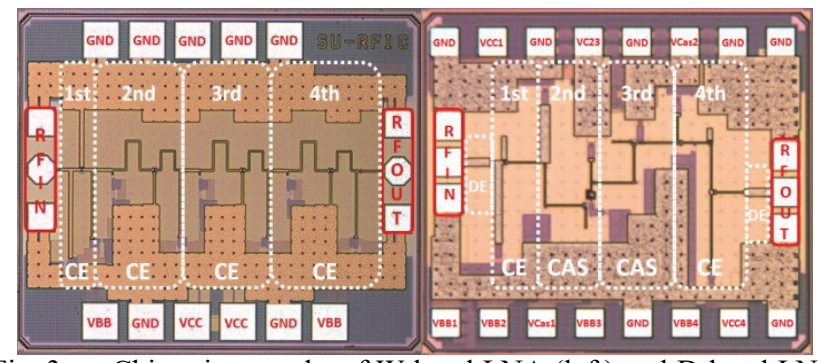

Fig. 3. Chip micrographs of W-band LNA (left) and D-band LNA (right).

\section{MEASUREMENTS}

Micrographs of the chips are shown in Fig. 3. The total area of the W-Band LNA is $0.6 \mathrm{~mm} 20.85 \times 0.7 \mathrm{~mm}$ ) including pads and the chip consumes only $8 \mathrm{~mW}$ of power from $1.3 \mathrm{~V}$ supply whereas the D-Band LNA draws $9 \mathrm{~mA}$ from $2.5 \mathrm{~V}$ supply and $5 \mathrm{~mA}$ from $1.5 \mathrm{~V}$ supply (total of $30 \mathrm{~mW}$ ) and occupies $0.56 \mathrm{~mm} 2(0.8 \times 0.7 \mathrm{~mm})$ of area including the pads.

S-parameters were measured on wafer at IHPMicroelectronics' facilities using separate setups for W-Band and D-Band LNAs. Measured peak gain of the W-Band LNA is $22.3 \mathrm{~dB}$ at $73 \mathrm{GHz}$ and drops to $12 \mathrm{~dB}$ at $110 \mathrm{GHz}$ and in very good agreement with simulation results. Average gain of the LNA is approximately $16.9 \mathrm{~dB}$. Also, the input and output return losses remain below $-10 \mathrm{~dB}$ from 75 to $110 \mathrm{GHz}$. As for the D-Band LNA, return losses are better than $-8 \mathrm{~dB}$ across the entire band and peak gain is measured to be $25.3 \mathrm{~dB}$ at 150 GHz. Gain of the LNA stays above $20 \mathrm{~dB}$ from $110 \mathrm{GHz}$ to 160 $\mathrm{GHz}$. The 3-dB bandwidth of the LNA is measured as $44 \mathrm{GHz}$. Noise figure measurements were performed at Millilab (VTT/Finland), and the NF results are shown in Fig. 6. Minimum NF of the W-Band LNA is $4.2 \mathrm{~dB}$, and $5.9 \mathrm{~dB}$ for the D-Band LNA.

It is worthwhile to calculate the effective noise bandwidth (ENB) of the LNAs to assess their viability in a radiometer system. Using the measurement results and the expression (1) given in $[5,6]$, the ENB of the W-Band LNA is found out to be $33.8 \mathrm{GHz}$, and $58.9 \mathrm{GHz}$ for the D-Band LNA. Table 1 illustrates the performance of the LNAs in comparison with the recent publications.

$$
E N B=\frac{\left[\int_{0}^{\infty} G(f) d f\right]^{2}}{\int_{0}^{\infty} G^{2}(f) d f}
$$

\section{CONCLUSION}

Two mm-wave LNAs have been designed in $0.13 \mu \mathrm{m}$ SiGe BiCMOS technology. The W-band LNA achieves $22.3 \mathrm{~dB}$ peak gain, $17 \mathrm{GHz} 3-\mathrm{dB} \mathrm{BW}$, and $35 \mathrm{GHz}$ of ENB while only consuming $8 \mathrm{~mW}$ of quiescent power. The D-band LNA has $25.3 \mathrm{~dB}$ peak gain, $44 \mathrm{GHz} 3-\mathrm{dB} \mathrm{BW}, 57 \mathrm{GHz}$ ENB and consumes $30 \mathrm{~mW}$ of quiescent power. The proposed LNAs are suitable for W-Band and D-Band radiometers and the state of the art performances have been demonstrated. 


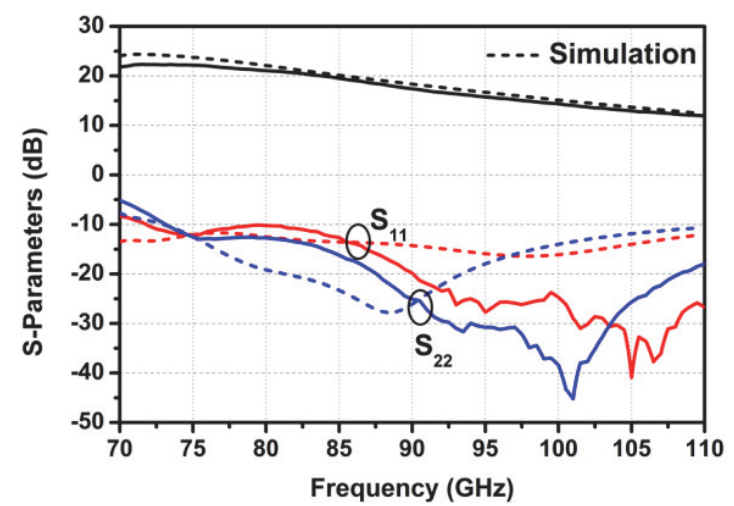

Fig. 4. Simulated and measured s-parameters of the W-band LNA.

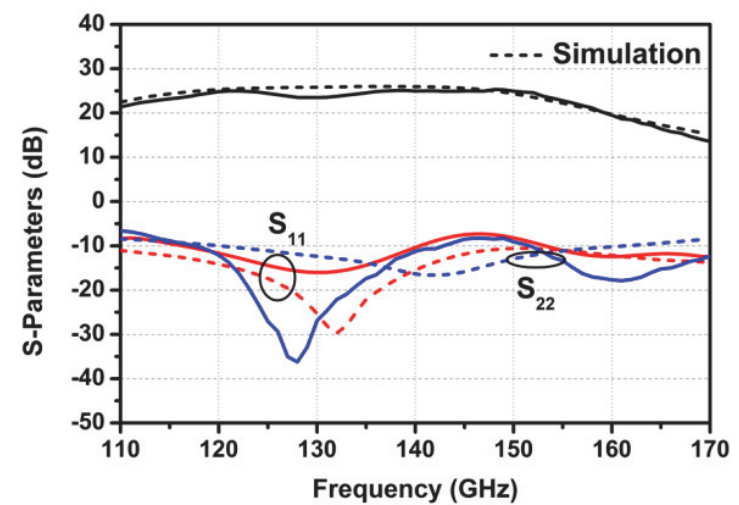

Fig. 5. Simulated and measured s-parameters of the D-band LNA.
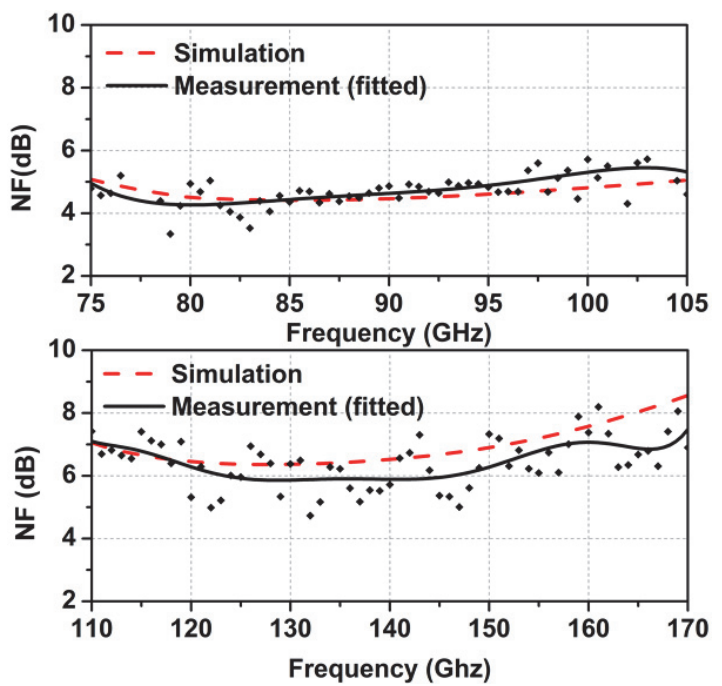

Fig. 6. Simulated and measured noise figure results of the W-band and the D-band LNAs

\section{ACKNOWLEDGEMENT}

This work is supported by The Scientific and Technological Research Council of Turkey under grants 114R079 and 115E101. The authors would like to thank Christian Wipf of IHP Microelectronics/Frankfurt(Oder) and Mikko Kantanen of Millilab-VTT/Helsinki for the measurements.
TABLE I

SUMMARY OF PERFORMANCE AND COMPARISON

\begin{tabular}{|c|c|c|c|c|c|c|}
\hline Ref. & Tech. & $\begin{array}{l}\text { 3-dB } \\
\text { BW } \\
\text { (GHz) }\end{array}$ & $\begin{array}{l}\text { Peak } \\
\text { Gain } \\
\text { (dB) }\end{array}$ & $\begin{array}{l}\text { NF } \\
\text { (dB) }\end{array}$ & $\begin{array}{l}P_{D C} \\
(\mathbf{m W})\end{array}$ & $\begin{array}{l}\text { Area } \\
\left(\mathrm{mm}^{2}\right)\end{array}$ \\
\hline [7] & $\begin{array}{l}90 \mathrm{~nm} \\
\mathrm{SiGe}\end{array}$ & $66-84$ & 34 & $3.5-4$ & 15.6 & 0.3 \\
\hline [8] & $\begin{array}{c}0.12 \mu \mathrm{m} \\
\mathrm{SiGe}\end{array}$ & $82-100$ & 27 & 7 & 27.6 & 0.26 \\
\hline [9] & $\begin{array}{c}0.18 \mu \mathrm{m} \\
\mathrm{SiGe}\end{array}$ & $70-97$ & 19 & 8.5 & 35 & $1 * *$ \\
\hline $\begin{array}{l}\text { This Work } \\
\text { (W-Band) }\end{array}$ & $\begin{array}{c}0.13 \mu \mathrm{m} \\
\mathrm{SiGe}\end{array}$ & $70-87$ & 22.3 & 4.2 & 8 & 0.6 \\
\hline [5] & $\begin{array}{l}90 \mathrm{~nm} \\
\mathrm{SiGe}\end{array}$ & $135-141$ & 36 & $>6.2 *$ & 45 & 0.36 \\
\hline [10] & $\begin{array}{l}0.13 \mu \mathrm{m} \\
\text { SiGe }\end{array}$ & $110-162$ & 32.6 & 4.8 & 28 & 1 \\
\hline [11] & $\begin{array}{c}0.13 \mu \mathrm{m} \\
\mathrm{SiGe}\end{array}$ & $120-134$ & 28 & $5.5-6.5$ & 12 & 0.4 \\
\hline $\begin{array}{l}\text { This work } \\
\text { (D-Band) }\end{array}$ & $\begin{array}{c}0.13 \mu \mathrm{m} \\
\mathrm{SiGe}\end{array}$ & $112-156$ & 25.3 & 5.9 & 30 & 0.56 \\
\hline
\end{tabular}

\section{REFERENCES}

[1] J. J. Lynch et al., "Passive Millimeter-Wave Imaging Module With Preamplified Zero-Bias Detection," in IEEE Transactions on Microwave Theory and Techniques, vol. 56, no. 7, pp. 15921600, July 2008.

[2] D. Notel, J. Huck, S. Neubert, S. Wirtz and A. Tessmann, "A compact $\mathrm{mmW}$ imaging radiometer for concealed weapon detection," 2007 Joint 32nd International Conference on Infrared and Millimeter Waves and the 15th International Conference on Terahertz Electronics, Cardiff, 2007, pp. 269-270W. H.

[3] J. Lahtinen, J. Pihlflyckt, I. Mononen, S. J. Tauriainen, M. Kemppinen and M. T. Hallikainen, "Fully polarimetric microwave radiometer for remote sensing," in IEEE Transactions on Geoscience and Remote Sensing, vol. 41, no. 8, pp. 1869-1878, Aug. 2003

[4] A. M. M. El-Sharkawy, P. P. Sotiriadis, P. A. Bottomley and E. Atalar, "A New RF Radiometer for Absolute Noninvasive Temperature Sensing in Biomedical Applications," 2007 IEEE International Symposium on Circuits and Systems, New Orleans, LA, 2007, pp. 329-332.

[5] T. Kanar and G. M. Rebeiz, "A Low-Power 136-GHz SiGe Total Power Radiometer With NETD of $0.25 \mathrm{~K}$," in IEEE Transactions on Microwave Theory and Techniques, vol. 64, no. 3, pp. 906914, March 2016.

[6] M. Tiuri, "Radio astronomy receivers," IEEE Trans. Antennas Propag., vol. AP-12, no. 7, pp. 930-938, Dec. 1964.

[7] P. Song, A. Ç Ulusoy, R. L. Schmid and J. D. Cressler, "A high gain, W-band SiGe LNA with sub-4.0 dB noise figure," 2014 IEEE MTT-S International Microwave Symposium (IMS2014), Tampa, FL, 2014, pp. 1-3.

[8] J. W. May and G. M. Rebeiz, "Design and Characterization of W -Band SiGe RFICs for Passive Millimeter-Wave Imaging," in IEEE Transactions on Microwave Theory and Techniques, vol. 58, no. 5, pp. 1420-1430, May 2010.

[9] L. Gilreath, V. Jam and P. Heydan, "A W-band LNA in $0.18-\mu \mathrm{m}$ SiGe BiCMOS," Proceedings of 2010 IEEE International Symposium on Circuits and Systems, Paris, 2010, pp. 753-756.

[10] E. Turkmen et al., " A SiGe HBT D-Band LNA with Butterworth Response and Noise Reduction Technique," in IEEE Microwave and Wireless Components Letters, vol. 28, no. 6, pp. 524-526, 2018.

[11] A. CC Ulusoy et al., "A SiGe D-Band Low-Noise Amplifier Utilizing Gain-Boosting Technique," in IEEE Microwave and Wireless Components Letters, vol. 25, no. 1, pp. 61-63, Jan. 2015 